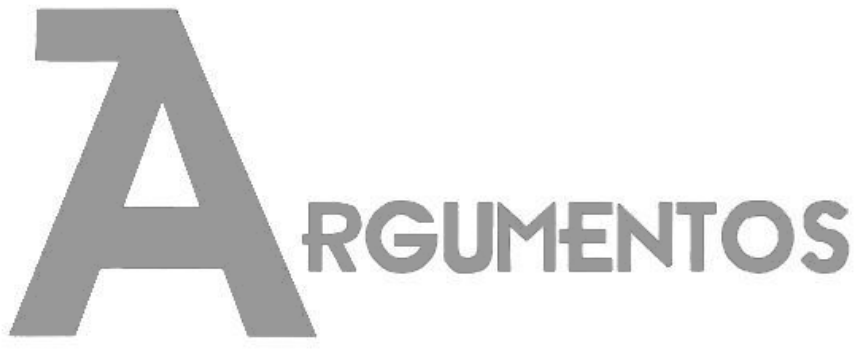

Vol. 16, n. 1, jan./jun. 2019 ISSN: 2527-2551 (online)

http://www.periodicos.unimontes.br/argumentos

\title{
Os hotéis do Programa de Braços Abertos: um novo contexto para o trabalho social e de saúde com pessoas vulneráveis
}

\author{
Ygor Diego Delgado Alves ${ }^{1}$ \\ Pedro Paulo Gomes Pereira ${ }^{2}$
}

Recebido em: 01/02/2019

Aprovado em: 30/04/2019

\begin{abstract}
Resumo: Detectamos uma carência de pesquisas específicas sobre o funcionamento dos hotéis do programa De Braços Abertos (DBA). Iniciativa do município de São Paulo, entre os anos de 2014 e 2016, que previa o acolhimento dos beneficiários nestes novos equipamentos. Assim, propomos uma pesquisa que descrevesse as principais características deste novo tipo de convivência criada no ambiente proporcionado pelos hotéis, alguns localizados nas franjas da região conhecida como Cracolândia. Através de uma etnografia, com a construção de relações próximas com técnicos da equipe gestora dos hotéis, pudemos verificar: (1) a busca constante da construção de vínculos com os beneficiários por parte dos técnicos, (2) a escuta qualificada e interessada das demandas e dramas cotidianos, e (3) a resolução de problemas em um ambiente contratual e participativo. O novo contexto proporcionado pelos hotéis do DBA, diverso ao da rua, juntamente com a intervenção dos profissionais abriu, em muitos casos, caminho para que a relação com o consumo do crack fosse alterada para um padrão mais controlado.
\end{abstract}

Palavras-chave: De Braços Abertos, Cracolândia, Etnografia, Crack, Vulnerabilidade .

\section{Los hoteles del Programa de Brazos Abiertos: un nuevo contexto para el trabajo social y de salud con personas vulnerables}

\footnotetext{
1 Doutor em Antropologia pela Universidade Federal da Bahia - Salvador, Brasil. Pós-doutorando em Saúde Coletiva pela Universidade Federal de São Paulo -São Paulo, Brasil. Bolsista pelo Consel ho Nacional de Desenvolvimento Científico e Tecnológico. E-mail:< antropologiaygor@yahoo.com.br >. ORCID: http://orcid.org/0000-0002-6730-3255.

2 Livre Docente pela Universidade Federal de São Paulo - São Paulo, Brasil. Professor Associado da Universidade Federal de São Paulo - São Paulo, Brasil. Professor do Programa de Pós-Graduação em Saúde Coletiva da Universidade Federal de São Paulo - São Paulo, Brasil. E-mail:< pedropaulopereira@hotmail.com >. ORCID: https://orcid.org/0000-0002-0298-2138.
} 
Resumen: Detectamos una carencia de investigaciones específicas sobre el funcionamiento de los hoteles del programa De Brazos Abiertos (DBA). Iniciativa del municipio de São Paulo, entre los años 2014 y 2016, que preveía la acogida de los beneficiarios en estos nuevos equipos. Así, proponemos una investigación que describa las principales características de este nuevo tipo de convivencia creada en el ambiente proporcionado por los hoteles, algunos localizados en las franjas de la región conocida como Cracolândia. A través de una etnografía, mediante la construcción de relaciones estrechas con los técnicos del equipo de gestión del hotel, pudimos comprobar: (1) la constante búsqueda de la construcción de vínculos con los beneficiarios por parte de los técnicos, (2) una escucha calificados e interesados a las demandas y dramas cotidianos, y (3) la resolución de problemas en un ambiente contractual y participativo. El nuevo contexto proporcionado por los hoteles del DBA, diverso al de la calle, junto con la intervención de los profesionales abrió, en muchos casos, camino para que la relación con el consumo del crack fuera alterada a un patrón más controlado.

Palabras-clave: Programa de Brazos Abiertos, Cracolândia, etnografía, Crack, Vulnerabilidad.

\section{The Open Arms Program hotels: a new context for social and health work with vulnerable people}

Abstract: We have detected a lack of specific research on the operation of Open Arms (DBA) hotels. An initiative of the municipality of São Paulo, between 2014 and 2016, which provided for the reception of beneficiaries in this new equipment. Thus, we propose research that describes the main characteristics of this new type of coexistence created in the environment provided by the hotels, some located in the fringes of the region known as Cracolândia. Through an ethnography, with the construction of close relations with technicians of the hotel management team, we were able to verify: (1) the constant search for the construction of links with the beneficiaries by the technicians, (2) the qualified and interested listener of the demands and day-to-day dramas, and (3) problem solving in a contractual and participatory environment. The new context provided by DBA hotels, unlike that of the street, coupled with the intervention of professionals has in many cases opened the way for the relationship with crack consumption to be changed to a more controlled pattern.

Keywords: The Open Arms Program hotels, Cracolândia, Ethnography, Crack, vulnerability.

\section{Introdução}

O artigo trata dos hotéis do De Braços Abertos (doravante DBA), um dos equipamentos que consideramos entre os mais relevantes do extinto programa municipal dedicado ao acolhimento de pessoas que habitam as ruas e usam crack na região central da cidade de São Paulo, a Cracolândia. São instalações por vezes lindeiras a cena de uso de drogas que, como veremos, se transformaram em algo tão socialmente relevante quanto pode ser uma acomodação humana na cidade. No entanto, se faz necessário, para a devida compreensão do caráter inovador destes hotéis, contextualizá-los na Cracolândia. Ou simplesmente Craco como a área é designada por muitos de seus frequentadores, tanto usuários de crack quanto profissionais que com 
estas pessoas trabalham. Está localizada na região central da cidade de São Paulo, e trata-se de uma imensa cena de uso de drogas que chegou a possuir milhares de frequentadores diários (ALVES, 2017). Este fenômeno não passou despercebido aos olhos da academia e foi objeto de dezenas de pesquisas sobre os mais variados aspectos como: as práticas de lazer e resistência que lá ocorrem (ADERALDO \& FAZZIONI, 2012; CALIL, 2016); as estratégias de autocontrole e autocuidado (ADORNO et al., 2014; RAUPP e ADORNO, 2015); as relações entre o Estado, o legal e o ilegal (ADORNO et al. 2013; DA SILVA e ADORNO 2013; RUI 2012); entre saúde e ambiente (COSTA, 2015), passando pela territorialidade e suas conexões com a cidade (FRÚGOLI JÚNIOR \& CAVALCANTI 2013; RUI et al., 2014).

Importante observarmos que os locais de uso do crack, inclusive a Craco, são percebidos como espaços vinculados, exclusivamente, ao consumo da substância, representados por imagens estigmatizantes associadas à dependência física (ROMANINI \& ROSO, 2014). O que não parece ocorrer de modo desinteressado, tendo em vista os futuros grandes empreendimentos possibilitados pela expulsão dos atuais moradores. “Mesmo quando querem revitalizar, chamam uma área de cracolândia. Isso é um modo de botar a mão, arranjar o apoio da classe dominante: aquilo é a cracolândia. Com isso se expulsa quem está lá, aquilo se desvaloriza" [...] (WISNIK; CORULLON, 2006)

Estigmatizar, desvalorizar, expulsar. Processo próximo aos fenômenos de gentrificação (BIDOU-ZACHARIASEN, 2003). Porém, que não cabe inteiramente dentro deste modelo (FRÚGOLI; SKLAIR, 2009), por não se implementar naquele espaço um procedimento de banimento claro das pessoas que lá residem em seus imóveis. Nem sempre serão adotadas práticas de expulsão, no correr do tempo algumas administrações municipais irão se opor e outras não. Veremos como a existência dos hotéis do DBA se tornaram o testemunho vivo da possibilidade de manter as pessoas que fumavam crack nas ruas habitando aquela parte do centro da cidade, porém, em condições qualitativamente distintas.

As pesquisas de campo sobre o DBA cobrem um leque relativamente amplo de aspectos e pontos de vista. São trabalhos que, por vezes, possuem uma abordagem que privilegia a repressão policial na Cracolândia, como em Magalhã es (2015) e Menezes (2016), que vê no DBA mais um programa voltado à repressão entre outras iniciativas violentas anteriores. Também em Frúgoli \& Chizzolini (2017) que chegam a comparar o 
DBA com ações pontuais e puramente repressivas como a operação Sufoco (Dor e Sofrimento). Calil (2015, p. 61) considerara o DBA como fruto de mera "disputa política". Além disso, a ideia de que este programa vinha para limpar o centro da cidade para a Copa de 2016 também foi largamente explorada por militantes contrários a esta iniciativa municipal.

Nasser (2016) tem por diferencial ter ido a campo e acompanhado as equipes de varrição compostas por beneficiários do DBA e conhecido seus trabalhadores, técnicos e agentes, principalmente os considerados de ponta. Além de ter testemunhado um pouco de seu trabalho cotidiano, por isso consegue descrever parte do funcionamento do programa. Afirma sero DBA uma política de concentração dos usuários de crack ao invés de promover sua dispersão, como feito pelas operações anteriores. Mas, ao mesmo tempo, e de modo até um pouco contraditório, sugere uma possível cumplicidade da prefeitura, na época do DBA, com a empresa Porto Seguro, que possui instalações na região, na sua intenção em acabar com a Cracolândia. Souza (2015) que também teve contato com os(as) trabalhadores(as) da saúde e assistência e, principalmente, com a Guarda Civil Municipal (doravante GCM), faz uma etnografia do trabalho da GCM a partir da implantação do DBA. A guarda será chamada a auxiliar na portaria dos hotéis, esta autora assinala que estes agentes públicos "perceberam a necessidade de separação dos modos de tratamento, entre quem deve ser punido e quem deve ser cuidado, ou seja, entre o traficante e o usuário" (SOUZA, 2015, p. 102). Um trabalho denominado Pesquisa de Avaliação Preliminar (RUI; FIORE; TÓFOLI, 2016), que foi levado à frente com auxílio de membros da administração municipal, também pôde se diferenciar dos que trazem uma visão mais negativa do programa. O contato direto com os trabalhadores do DBA, além é claro, dos próprios dados obtidos na pesquisa, parece ter feito toda diferença no tom adotado frente ao empreendimento do poder municipal.

Os equipamentos destinados ao abrigo da chamada população em situação de rua - compreendida como um "Grupo populacional heterogêneo, composto por pessoas com diferentes realidades, mas que têm em comum a condição de pobreza absoluta e a falta de pertencimento à sociedade formal" (MOTTA, 2005, p. 3) - possuem entre as modalidades ofertadas o Hotel Social, destinado "aos usuários independentes e socialmente ativos através de convênio vinculado com hotéis" (PREFEITURA DE SÃO 
PAULO, 2009, p. 116). Assim como fazem parte dos serviços oferecidos os Centros de Convivência, Centros de Acolhida e Repúblicas. Estas últimas funcionam em sistema de cogestão e tem como público, além de idosos, "pessoas com deficiência, mulheres e homens com vivência de rua". (PREFEITURA DE SÃO PAULO, 2009, p. 120-121). Pudemos verificar em nossa pesquisa etnográfica que nos Centros de Acolhida não existem instâncias locais formais de participação, de fato, dos acolhidos. Nem na gestão dos equipamentos, tampouco na fiscalização dos gastos executados com as verbas municipais que os mantém.

Não há na bibliografia disponível uma descrição do funcionamento dos hotéis, seu impacto sobre os antigos beneficiários do DBA e sobre as pessoas que lá trabalham. 0 documentário que tem por título o nome de um dos hotéis do programa, o Hotel Laide, dirigido por Debora Diniz, mostra como o cuidado, e não a abstenção do uso do crack, está no centro das prioridades nos hotéis. Portanto, não estranhamos que três a nos após o encerramento do DBA, parte dos hotéis permaneçam ocupados e funcionando. A resiliência deste novo tipo de equipamento nos indica a necessidade de melhor compreendê-los. Pois resgataram parcela do que o município havia aprendido a partir dos hotéis sociais, como o conveniamento, antes feito pela Secretaria Municipal de Assistência e Desenvolvimento Social (doravante SMADS), porém muito lhes foi acrescentado como equipamento voltado à população de rua que fuma crack. Para compreendermos isto será também necessário saber um pouco do funcionamento do programa.

\section{Metodologia}

O artigo que aqui apresentamos surgiu de pesquisas na região paulistana conhecida como Cracolândia. De início, o primeiro autor deste texto ali realizou uma etnografia por dois anos. Em seguida, procurando compreender as políticas públicas para o consumo do crack, realizamos em conjunto uma pesquisa, de fevereiro de 2016 a julho de 2018, por meio de observação participante, entrevistas e acompanhamento da vida cotidiana dos profissionais de saúde, assistência e pessoas que consomem crack. Assim, este é um trabalho no qual os autores já vêm dialogando há mais de quatro anos e que propiciou que ambos participassem da redação, concepção e revisão final do 
artigo - o que pode ser percebido por formas verbais e pronominais características da primeira pessoa do plural.

Decidimos apresentar neste artigo uma visão dos hotéis do DBA, e do trabalho desenvolvido pelas equipes profissionais que neles atuam, sob o ponto de vista dos técnicos. Os beneficiários do programa, com quem tivemos interlocução, serão protagonistas em outra publicação. Esta decisão se deve ao fato de não pretendermos aqui fazer o confronto destas diferentes perspectivas nem nos valer de uma para sustentar a outra. Acreditamos que a vivência dos trabalhadores contratados ao término do programa, explicitada em suas falas e em nossas observações de campo, possui relevância suficiente que justifique sua descrição e análise. Acabamos por ter uma inserção de proximidade, que nos remeteu às vivenciadas pelos nossos antecessores e contemporâneos brasileiros na pesquisa sobre o uso de drogas, tais como Velho ([1975] 2008), Fernandez (2007), MacRae e Simões (2000), Malheiros $(2012,2013)$ entre outros, que foram a campo e conviveram com as pessoas que usavam drogas tornadas ilícitas, ou seja, que fizeram etnografia do uso destas drogas. Como também foi o caso dos estudos de Bourgois (2006), com vendedores de crack e de Bourgois e Schonberg (2009), realizado entre usuários de heroína. Isto, dentro da melhor tradição do ofício antropológico que propõe a criação de uma narrativa a respeito do outro, que parte das relações construídas no campo. Quando se adentra na intimidade cultural nativa (HERZFELD, 1997) como procuramos fazer, certos relacionamentos passam a ser constantemente negociados. Este foi o caso de nossa relação com os profissionais do DBA dentro dos hotéis. O tipo e profundidade das informações que daí surgiram dependeram, grandemente, da qualidade destas relações. Antes de obter informações a respeito das relações entre nossos interlocutores, construímos relações com eles. É um movimento que vai das relações com eles para o saber sobre as relações entre eles (STRATHERN, 1999).

\section{O programa De Braços Abertos}

O DBA foi um programa do município de São Paulo destinado ao atendimento das demandas levantadas, durante o ano de 2013, entre as pessoas que residiam na rua e consumiam crack na região paulistana conhecida como Cracolândia, localizada no bairro da Luz, centro da cidade. Com caráter intersecretarial envolveu, primordialmente, as 
áreas municipais da Saúde, Assistência, Trabalho, Direitos Humanos e Segurança Urbana. Foi concebido para ofertar abrigamento, tratamento de saúde, alimentação, atividade ocupacional, capacitação profissional e auxílio financeiro aos beneficiários incluídos na execução de serviços de zeladoria nas ruas e teve início dia 14 de janeiro de 2014. A adesão ao programa se deu nos dias anteriores, ao serem contratadas mais de 300 pessoas pelo Programa Operação Trabalho (POT) da Secretaria Municipal do Desenvolvimento, Trabalho e Empreendedorismo (SDTE) para trabalharem em atividades de limpeza na região. Ocupação pela qual passaram a receber um auxílio financeiro no valor de $\mathrm{R} \$ 15,00$ por dia de trabalho, incluindo os finais de semana para os assíduos. Hospedados em hotéis da região tinham alimentação correspondente a três refeições diárias e cursos de capacitação ofertados a partir de aptidões e demandas dos beneficiários.

Após acordarem e saírem do hotel, se dirigiam ao restaurante Bom Prato para tomarem o café da manhã, com a presença de um orientador social da SDTE responsável por uma equipe de 20 beneficiários. Dificilmente a equipe estará completa, os ausentes serão objeto de busca ativa nos hotéis por parte dos 44 orientadores socioeducativos da SMADS e agentes comunitários da Secretaria Municipal de Saúde (doravante SMS). As informações sobre a ausência no trabalho, para a posterior busca ativa, são obtidas por estes profissionais após o café da manhã, no local de saída das equipes de trabalho. Em seguida, os agentes sociais da SMADS e agentes comunitários de saúde, também responsáveis por cada grupo de 20 beneficiários, se dirigem aos hotéis para visitá-los e verificar os motivos da ausência na frente de trabalho. Entre às 13 e 14 horas, o trio composto pelos agentes sociais da SMADS, agentes comunitários de saúde da SMS e orientadores sociais da SDTE se reúne para discutir as diversas demandas surgidas. Os agentes comunitários de saúde eram os únicos não disponíveis na proporção de um por grupo de 20 pessoas, mas apenas um por hotel onde se hospedem beneficiários.

A busca ativa é feita dentro dos hotéis com os membros do trio indo de porta em porta. Os membros da equipe técnica originalmente trabalhavam apenas em um mesmo hotel. Contudo, devido à necessária flexibilidade exigida pelas características dos beneficiários, havia, no início do DBA, uma considerável flutuação deles entre os apartamentos e mesmo entre os hotéis. Isto se dava pelos mais variados motivos, des de separações de casais, passando pelo desejo de ter uma acomodação melhor, até a 
simples curiosidade de conhecer e se alojarem quarto ou hotel diferente. Assim, os trios deviam dar conta de 20 beneficiários distribuídos nos mais variados hotéis. Isto marcava um dos pontos fortes do programa: o atendimento integrado, individualizado e integral ao beneficiário, proporcionado pelo trabalho de profissionais ligados às áreas de saúde, assistência e trabalho em contato diário entre si.

Os antigos moradores dos barracos e malocas da Craco, por sua vez, tentam adaptar o quarto de hotel à vida costumeira na rua e, ao mesmo tempo, mudam o estilo comum de ocupação de um hotel para melhor adaptá-lo ao seu modo de vida em transição. Por exemplo, ocupam os corredores e escadas para conversas elazer, flutuam entre os quartos e prédios e alugam vagas para terceiros nos finais de semana, quando não havia acompanhamento dos agentes sociais da SMADS. Estes estavam presentes todos os dias úteis na portaria e procuram estabelecer certo controle sobre a ocupação dos quartos. A flutuação não se dava livremente, mas por via de pedidos às agentes sociais e particularmente a uma assistente social com larga experiência na região. Esta assistente social conhecia, no início do DBA, pelo nome ou apelido praticamente a totalidade dos beneficiários que eram antigos moradores ou frequentadores assíduos da Cracolândia.

\section{Os hotéis do De Braços Abertos}

No início do DBA, os hotéis tiveram de ser lindeiros ao "fluxo", como é chamado o centro a cena de uso de crack. Uma segunda leva de contratações pôde colocar à disposição dos beneficiários do programa hotéis de melhor qualidade e um pouco mais afastados. As equipes para gerenciar os novos hotéis foram contratadas no último ano do DBA, 2016, prevendo sua ampliação e na busca por melhorar a gestão. Os contratos passaram a ser geridos pela SMS no lugar da SDTE.

A mudança na gestão dos hotéis e a chegada de novos técnicos, como é o caso de Rodriguinho, contratado pela organização social Instituto de Atenção Básica e Avançada à Saúde (IABAS), pareceu estar longe de ter sido algo sem os esperados percalços impostos por um momento tão pouco propício: o final do ano de 2016, crepúsculo da gestão Haddad frente à prefeitura de São Paulo. No início de 2017, o DBA nos hotéis começa a ser desmontado. Os GCM que haviam sido treinados em mediação de conflitos 
e passaram a fazer parte da equipe gestora dos hotéis são afastados. O técnico Rodriguinho ${ }^{3}$, trabalhador social em um dos hotéis do programa, nos explica, em 2017, a proposta inicial para a GCM.

Eles trabalharam de forma civil ali na entrada e saída dos moradores e fazendo alguma ou outra intervenção. E foi muito bacana na verdade com o tempo, né. A gente foi trocando ideia e eles foram tirando essa lavagem cerebral que o militarismo faz na cabeça das pessoas e entenderam que os moradores dos hotéis são pessoas como a gente, né? Só que com questões outras. E, agora, com o desmantelamento do DBA, a Secretaria de Segurança saiu e tiraram o gerenciamento dos hotéis justamente para acabar com o programa.

Policiais da GCM foram treinados em mediação de conflitos e redução de danos para poderem trabalhar nos hotéis. Isto dá prosseguimento a tentativas anteriores, sempre frustradas, de articulação da Saúde com o Programa Prioritário de Proteção a Pessoas em Situação de Risco, da GCM. Foi, portanto, uma mudança tão profunda que pôde reverter as expectativas e resistências mais arraigadas entre os técnicos que também são, em parte, militantes políticos em favor dos direitos dos frequentadores da Cracolândia. A intervenção destes policiais difere imensamente do que comumente se via anos anteriores nos ataques do poder público sobre as pessoas mais vulneráveis da região da Luz. Testemunhamos, em nossa etnografia, quanto o serviço de portaria foi um desafio constante para o DBA: tentar evitar a entrada de pessoas alheias ao programa que colocassem em risco o bem-estar dos beneficiários dentro dos hotéis. A GCM, ao desempenhar este papel, dava grande contribuição para construção de um ambiente seguro e mais voltado à mudança de estilo de vida. O treinamento inicial parece ter tido o efeito de ampliar a visão destes guardas para uma nova forma de interação com pessoas vistas como usuários de droga; e se completa no diálogo e trabalho conjunto com a equipe gestora do hotel.

Com o fim do DBA, a partir de 2017, decorrência da posse do novo prefeito, as reuniões que deveriam ocorrer de supervisão das equipes com a SMS cessam. As ocorrências cotidianas, dos mais variados tipos que se possa imaginar em um serviço público com características de acomodação transitória, deixam de ter qualquer tipo de

\footnotetext{
${ }^{3}$ Todos os técnicos dos hotéis, com quem tivemos interlocução em nossa pesquisa, são apres enta dos com nomes fictícios.
} 
apoio do poder municipal; muito pelo contrário, há um ostensivo boicote aos beneficiários do programa e os técnicos que têm de lhes prestar todo tipo de auxílio passam a se organizar por conta própria.

Conversamos com alguns destes, então, novos técnicos. Também dialogamos com os antigos, que já trabalhavam nos hotéis antes deles terem equipe específica, que reconheceram as dificuldades iniciais dos novos contratados pelo IABAS. Mariana, 35 anos de idade, trabalhadora social de um hotel afastado da Cracolândia chegou a nos informar de problemas mais sérios.

Só que é assim: Deu um pouco errado por que a galera não [...] são pessoas que são usuárias de crack, não dá para falar de qualquer jeito, tem que saber falar com essa população.

Senão eles se voltam contra você mesmo! Eles agrediram a equipe. A equipe continua dentro dos hotéis.

Houve muitas agressões. Entendeu? Os usuários não aceitavam a equipe. A equipe nos hotéis, né. E foi turbulento no início, mas agora parece que tá indo. Entendeu?

Em pouco tempo o entrosamento entre os trabalhadores sociais, da Saúde e do POT, que se encontravam a mais tempo com a responsabilidade de dar seguimento às ocorrências e todo tipo de necessidade apresentada pelos hóspedes/beneficiários, com a nova equipe e desta com as pessoas que residiam nos diferentes dispositivos de moradia, melhorou. Embora, a falta de supervisão e apoio pudesse gerar situações na qual algum técnico ou agente social antigo pudesse tomar uma postura de afastamento com relação às demandas cotidianas, em um comportamento condizente com a nova administração, ouvimos reclamações neste sentido. O técnico Jonas, 38 anos, que também trabalha em um dos hotéis e contratado em 2016, pela IABAS, nos falou a respeito das possibilidades abertas pela presença de uma equipe profissional no local de moradia dos beneficiários.

A gente consegue essa aproximação muito melhor né, o vínculo a gente consegue fortalecer muito mais né, a confiança, enfim, e esse tipo de trabalho eu acho que é mais próximo do beneficiário, da vida do cara, entender o cara como um ser completo né, suas particularidades, enfim, você consegue entender mais até porque tá ali. 
Pichon-Rivière (1995) em sua Teoria do Vínculo, o considera como sendo a estrutura dinâmica estabelecida na relação sujeito-objeto. A coerência e os vínculos em um grupo se sustentam sobre o jogo entre a assunção e adjudicação de vários papéis. Assim, a comunicação se estabelece no vínculo a partir do momento em que ambos sujeitos assumem o respectivo papel adjudicado pelo outro. Em comparação com a atividade anterior de Jonas como supervis or de equipe de zeladoria pelo POT, o trabalho no hotel permite uma maior confiança e vínculo com os beneficiários. Também podemos entender um pouco desta fala, primeiro, reconhecendo em Jonas, e nele em muitos outros técnicos e agentes, um trabalhador social motivado e profundamente empático em sua relação com os beneficiários. Seu trabalho é tanto melhor, e aparentemente mais gratificante e motivador, quanto mais espaço lhe proporciona para estar próximo às pessoas que geram o conteúdo de suas tarefas cotidianas.

A escuta tem muito esse papel terapêutico né, e essa escuta ela se transforma numa reflexão, não numa só né, mas numa reflexão dupla para o beneficiário né, há uma troca muito mais eficaz, há uma troca muito mais profunda disso né. Você está conversando com ele hoje, amanhã ele tá arrependido, depois a gente fala no mesmo assunto, e a gente continua essa reflexão né, eu acho que é uma reflexão mais potente no caso né. Diante do ponto de vista do beneficiário, diante do ponto de vista do técnico né, enfim.

Muito se escreveu sobre a psicopatologia do trabalho, como no clássico de Dejours (1988) e seu conhecido exemplo da exploração do sofrimento das telefonistas, que hoje poderiam, talvez, serem representadas pelas operadoras e operadores de telemarketing. No caso destas trabalhadoras, o conteúdo da tarefa, atender os usuários do sistema de telefonia, causava sofrimento e fazia com que as telefonistas quisessem se livrar dos usuários o mais rapidamente possível, o que aumenta sua produtividade. Jonas, por sua vez, não sente nenhum alívio em se livrar dos moradores e seus problemas, se sofrimento há, parece se ligar mais à falta de espaço de tempo para melhor, como nos confidenciou, colher as "questões da vida". Para tanto, e ainda em contraposição ao caso das telefonistas, se faz necessária uma cada vez maior aproximação, a vida parece ser contada em sussurros ao pé do ouvido, murmurada, assoprada por lábios que respondem e procuram a mais importante possibilidade aberta 
pela "confiança": o vínculo. Termo onipresente no discurso dos técnicos e agentes que trabalham na Cracolândia, vínculo, parece serfruto da força de uma troca estabelecida através da escuta de qualidade, interessada e competente, ou seja, que possa dar resposta às demandas sempre urgentes de quem vive no limite, porque a impaciência também tem suas razões. Este encolher da distância como método gnosiológico em que escutar condiciona o entender, busca no conjunto das particularidades, que só podem se revelar com o tempo, apreender o indivíduo: a completude do ser. Só assim, o morador pode ser transmutado em "caso", a ser objeto de trabalho de equipe, de diálogo, de debate, de busca por alternativas de solução das mais diversas "questões", como Jonas chegou a descrever. Que se formularam após aproximação, escuta e vínculo, para só então poderem ter alguma ressonância no conjunto dos técnicos que irão sobre elas debruçar e refletir. Reflexão que se inicia e prolonga no contato empático diário. Não é com qualquer pessoa que se abre o jogo sobre dramas familiares e amorosos. Ou, ao menos, nem todos possuem tamanha desenvoltura e desprendimento, assim a escuta é troca, ato reflexivo cotidiano sobre atitudes tomadas no âmbito do hotel e fora dele; que permite apreender e formular certo "ponto de vista". Jonas, assim irá nos descrever, muito sucintamente, o processo reflexivo mediado pela prática.

[...] você consegue fazer essa reflexão com ele né. Você consegue fazer essa reflexão, por exemplo, quando é na questão da Saúde.

O cara está lá com uma tuberculose, está lá com HIV, enfim, tá lá com uma série de problemas né, e a gente coloca, e a gente vai refletindo juntos a qualidade de vida do cara.

Isso tem vinte e quatro horas aqui, tem o médico, tem a questão da Saúde. Então essas reflexões né, e aí são reflexões permanentes, que a gente consegue dar esses encaminhamentos práticos mesmo.

A retirada de um documento, primeiro passo para uma espécie de reinserção na legalidade, a ida ao médico e o iniciar de um tratamento são ações precedidas por processos reflexivos com idas e vindas, arrependimentos, quedas. Fatos transformados em ocorrências que são transmitidas de um turno para o outro, no interior de uma equipe técnica, 24 horas por dia, 7 dias por semana, no ritmo dado pelo batimento do "fluxo", sempre lá, à disposição, prolongando dias e noites. Pense e fume, fume e pense. 
Eu acho que é uma coisa quando você está assim vinte e quatro horas né! Você troca o plantão, você troca o técnico, mas a atenção continua, até porque a equipe conversa muito. Agente tem um diárioné, quea gente toda troca de plantão, a gente conversa pelo menos uma meia hora.

Reflexão constante, diálogo, anotação, verificação, acompanhamento. Conversa diária com o beneficiário do DBA, o que se forja aqui é uma relação social primária, do tipo familiar que também é encontrada na rua (YUNES, 2001). Nas palavras de Jonas: “O vínculo próximo né, essa coisa mais humanizada no sentido de você pegar, tocar, dar bronca. "Você tem que dormir porque amanhã cedo você vai ter que trabalhar" Aquela bronca do pai, aquela bronca da mãe mesmo sabe?" O vínculo, o toque, a bronca, atos comuns em família, protetivos, interessados. O trabalho de construção de vínculos leva Jonas a reproduzir a instituição vinculante por excelência. A falta do sangue, da hereditariedade impulsiona uma construção consciente, refletida, sistemática de uma instituição de tipo nova no interior do hotel. O que Ihe falta em genética tem de ser compensado com esforço, método, persistência e empatia.

Os técnicos da carreira da Saúde e Assistência visitam os hotéis em resposta às demandas formuladas pelas equipes, noutro momento podem estar no "fluxo" ou nas ruas do bairro realizando os mesmos atendimentos, de modo que o serviço se projeta sobre o hotel, a rua e a cena de uso. "É! É que é assim: Esse pessoal que passa no hotel também trabalha na rua e circula muito na rua né? Ali no "fluxo" e no território ali. Esse pessoal também tem um vínculo, né". São palavras de Lumena Almeida Castro Furtado que trabalhou na coordenação do DBA, na fase final do programa quando as novas equipes dos hotéis foram contratadas. Se atende quem tem vínculo e se cria vínculo pelo atendimento, diariamente há uma busca pela atenção integral na formulação de um Plano Individual de Tratamento (PIT) pela Saúde e de um Plano Individual de Atendimento (PIA) pela Assistência, que podem ser ingredientes naquilo que Lumena Almeida Castro Furtado, entre outros, chama de Projeto de Vida (ANTROPOLOGIA DAS DROGAS, 2017).

Garcia, Tykanori e Maximiniano (2014, p. 154) ao analisarem o programa De Braços Abertos enfatizam seu caráter produtor de sujeitos políticos, coletivos e contratuais. Livres do que denominamos ditadura do corre (ALVES, 2017), os beneficiários do DBA passam a viver numa outra "temporalidade cotidiana" e gozar de 
uma nova perspectiva. Os contratos estabelecidos para a convivência nos quartos e demais dependências dos hotéis demonstram a validade desta importante caracterização do DBA; muito agudamente percebida por Ivana, com 26 anos de idade e técnica, com formação em psicologia, em um dos hotéis do programa. Ao expor os motivos pelos quais não seria producente encaminhar as pessoas dos hotéis para centros de acolhida.

Eu não acredito não, eu não acredito que o pessoal vá! O pessoal, eu acho que prefere ficar na rua sabe? Muitos deles já passaram por abrigos, já passaram por Centros de Acolhida né, muitos não, quase todos né, sei lá, noventa por cento pra mais. Isso, mas se adaptou ao hotel, é que é uma coisa diferente né, é uma liberdade mais acentuada né, se sente mais em casa, mais cômodo, tem as coisas dele né, tem a cama que é dele né, ele arruma como ele quer. Mas assim, por exemplo, tem horário de visita, limpeza de quarto né, que a gente já combinou, e aía gente combina com as coisas com eles dentro das nossas assembleias, que a gente faz.

Nos centros de acolhida de São Paulo, a prática política deveria ser a regra, mas não é. As assembleias, quando ocorrem, têm um poder de deliberação reduzido e as normas podem, assim, ser impostas de cima para baixo pela equipe gestora. O espaço para a negociação costuma ser pequeno e os horários rígidos. Isto parece dificultar em muito aquilo que Goffman (1987, p. 159) designou como ajustamentos secundários: estratégias de resistência dos indivíduos às manobras de dessubjetivação e objetificação por parte do poder em instituições. Estes ajustamentos dizem respeito a [...] "qualquer disposição habitual pela qual o participante de uma organização emprega meios ilícitos, ou consegue fins não-autorizados, ou ambas as coisas, de forma a escapar daquilo que a organização supõe que deve ser e obter" [...] As instituições são capazes de se adaptar a estas forças contra hegemônicas, mesmo com perda de parte das obrigações dos participantes. Os hotéis, com seu assembleísmo e corpo técnico aberto a interlocução, parecem possuir maior plasticidade organizacional em relação aos centros de acolhida. Além de uma forma de acomodação das pessoas em quartos diferenciada. Ter uma cama para chamar de sua, como ocorre nos hotéis, difere em muito de ter uma cama qualquer para dormir, situação vivida nos centros de acolhida. Espaço e permissão para 
manter o animal de estimação também importa muito. Rodolfo, assistente social com passagem em alguns hotéis do DBA como técnico contratado pela Saúde, esclarece.

Isso também é um êxito no nosso programa De Braços Abertos, que a porta é aberta, que eles entram e saem a hora que eles querem da casa deles, do hotel, eles não têm hora pra chegar e nem pra sair entendeu? Isso para mim é muito importante.

Ter um teto sobre a cabeça é menos que ter sempre o mesmo teto, no mesmo quarto e com os mesmos "parças". Existe maior liberdade e, ao mesmo tempo, maior estabilidade, um ganho em termos do que J.P. Grund (1993) chama de estrutura de vida: uma quantidade maior de vínculos afetivos, compromissos, obrigações e responsabilidades. Itens considerados, por este autor, fundamentais para uma melhor relação com o uso de drogas. Isto tem uma grande influência sobre o padrão de uso do crack e do álcool que pode se modificar de um uso constante, 15 pedras por dia, para ocasional. A continuação de nossa conversa com o assistente social Rodolfo expõe o modo como a estrutura de vida opera.

No hotel que eu tô agora, por exemplo, eu vejo muito isso, por mais que tenha gente que chegue às quatro da manhã que é o caso do Miguel ${ }^{4}$, o vulgo Zebrinha, ele tem sessenta anos de idade, fez agora a semana passada, ele não falta nenhum dia sequer no trabalho.

Ele dorme de dia, não tanto, quando é umas seis horas ele vai até o Bom Prato comer, que é ali onde a gente oferece comida para eles comerem, eles vão até o Bom Prato. Ele volta toma um banho e vai para o fluxo.

Ele volta todos os dias indubitavelmente entre as três e meia e quatro da manhã. Ele chega toma banho, a gente conversa um pouco, ele vai dormire ele acorda as sete para trabal har. Todo dia. Ele conseguiu faze ruma rotina, coisa que normalmente o usuário não consegue fazer né?

O caso de Zebrinha mostra muito bem como compromissos e um local para dormir podem ter grande impacto sobre estrutura de vida da pessoa, composta por um importante conjunto de variáveis que guiaram o estudo de Grund e que se referem a padrões regulares de atividades laborais, recreativas e domésticas que moldam e constrangem o dia a dia de usuários de drogas. Também se enfatiza a importância das

\footnotetext{
4 Todos os beneficiários são citados com nomes fictícios.
} 
atividades regulares (tanto convencionais quanto as relacionadas ao uso de drogas) que estruturam os padrões diários como chaves da estrutura de vida. Parece lógico, para Grund, incluir os relacionamentos pessoais, compromissos, obrigações, responsabilidades, metas e expectativas que são exigentes e, simultaneamente, têm valor social (afetos) ou econômico (salários) como determinantes igualmente importantes. Contatos regulares com usuários controlados e não usuários, como o pessoal técnico dos hotéis, são também de considerável importância. Assim como, são importantes para Grund a participação nas estruturas e atividades não motivadas primariamente por incentivos relacionados a drogas.

A importância da estrutura de vida é muito claramente demonstrada pela sua ausência, como representado pelo sacizeiro soteropolitano, apresentado na tipologia de uso de crack de Malheiros (2013); e em Fernandez (2007) com o padrão pé na jaca para consumidores de cocaína cheirada. A conquista propriamente política e contratual de que falam Garcia, Tykanori e Maximiniano (2014, p. 154) vem a partir da realização de assembleias genuinamente deliberativas, em que a equipe não abre mão de sua parcela de responsabilidade, como nos descreve a trabalhadora social Ivana, da SMADS, lotada em um hotel afastado da cena de uso desde antes da composição das equipes da IABAS em 2016.

A gente deixa algumas coisas, mas aqui não é uma zona né.

O som. A gente permitiu o som, uso de rádio e tal né.

"Olha, final de semana dá pra ficar o som ligado até um pouco mais tarde, até meia noite né, no meio de semana vamos colocar ele até as dez".

Quando chega no hotel e tal, dez, onze horas o pessoal já tá dormindo, então um som mais baixo né, um som que abranja somente o quarto do cara ali né.

Os beneficiários do DBA hospedados nos hotéis, mesmo após o fim oficial do programa, não poderiam ser sobrecarregados com obrigações burocráticas em nome da democracia, com responsabilidades e decisões capazes de indispor uns com os outros. Portanto, existem assuntos que a equipe técnica não pode abrir mão de decidir sem correr o risco de prejudicar ou colocar um morador em perigo. No exemplo levantado por Ivana fica claro que visitas íntimas poderiam inimistar ocupantes de um mesmo quarto. Qualquer ato mal interpretado, como um desrespeito qualquer, traria consigo o 
potencial de provocar hostilidades. Benedito Mariano, em entrevista que nos concedeu em seu gabinete de secretário de segurança urbana, comparou o "fluxo" a um "pátio de cadeia", onde imperariam as regras do crime organizado, O PCC, semelhantes as descritas por Biondi (2018).

O termo "pátio de cadeia" nos remete a ideia de que as relações sociais dentro de determinado contexto social não devem ser consideradas apenas em sua forma socioestrutural. Outras modalidades, como a "communitas", servem de base para a constituição de relações sociais entre indivíduos não segmentados em posições sociais. Nesta forma de se relacionarem, os indivíduos podem interagir com autêntica reciprocidade. Marcada pela espontaneidade e imediatidade, a "communitas" opõe-se ao caráter jurídico/político da estrutura. Malgrado a satisfação que os participantes possam derivar de tal situação, a "communitas" estaria, por razões materiais de sobrevivência do grupo, condenada a ter uma vida curta e, em decorrência disto, as relações entre indivíduos retornariam a relações normatizadas entre "pessoas sociais". (TURNER,1974, p.161)

A Cracolândia aproxima-se da "communitas" de Victor Turner, ela seria uma experiência de reciprocidade imprevisível e única. Uma existência em êxtase, ou seja, fora das normas e suas posições estruturais. Assim, a "communitas" aparece como uma grande tentação humana, a tentação do gozo dos sentimentos prazerosos proporcionados pela liberação das inclinações pessoais das amarras dos desejos e necessidades do social estruturado.

Na Cracolândia, antes do Programa DBA, a estrutura mais próxima aos usuários de crack era representada pelas "pessoas sociais" dos "disciplinas", "primos" e "irmãos" do PCC. As relações diretas e imediatas entre indivíduos poderiam ser vividas no interior do "fluxo". A atração do "fluxo" é devida ao seu aspecto de "communitas", ou seja, indivíduos em relação direta uns com os outros, conversando em pequenos grupos e movimentando-se entre eles. O passardas horas se dá entre velhos e novos conhecidos, todos animados pelo exercício da treta - troca recíproca de bens variados afeitos ou não à parafernália de uso do crack - e pela "sintonia", agradável sensação de cumplicidade, proporcionada pelo uso.

Portanto, retomando as considerações da trabalhadora social Ivana, os costumes sexuais e modos do sistema penitenciário não se adaptam, necessariamente, à vida no 
hotel. O que não significa, de modo algum, impedir a formação de vínculos dura douros entre casais, mas, aí, outras regras entram em cena. Nas palavras de Ivana:

Esse tipo de coisa. Agora vamos colocar uma coisa que é assim, que é a equipe que decide né: Não vai ter visita íntima, por exemplo, né. Porque, primeiro que são quartos coletivos né, e assim não dá para transformar o hotel naquela lógica de cadeia né, a gente tenta tirar isso o máximo possível. Isso! Não, isso, isso, aí a gente barra, não é permitido não. Isso é assim: Se a pessoa tem um companheiro ou uma companheira, existe um quarto de casal né.

No início do DBA, a deliberação sobre mudanças na ocupação dos quartos era atributo de uma assistente social com alguns anos de experiência na Cracolândia, por conta de seu trabalho no Serviço de Assistência Especializada (SAE) dos Campos Elísios. Algo analisado anteriormente em Alves (2017) e que também se encontra presente de certa forma em Garcia, Tykanori e Maximiniano (2014) é a importância, não só do cuidado horizontal, uns com os outros, mas, das diversas sanções que vêm a exercer constrangimento ao uso de crack. Desde Howard Becker (2009 [1963], p. 52) que a importância dos "controles sociais" é conhecida por quem pretende estudar o uso de drogas sob um ponto de vista antropológico.

\section{Novas possibilidades}

Antes de serem acomodados nos hotéis, os beneficiários do DBA costumavam passar seus dias nas calçadas da Luz ou caminhando pela cidade. Em Alves (2017) se observou como o crack possui um certo espírito andarilho, como impõe o movimento que se dá, não poucas vezes, com os pés desnudos plantados no chão. A cidade é o meio através do qual o corpo se move na "caminhada", enquanto as mãos ficam livres para trabalhar. O sentido tátil dos pés desnudos permite reconhecer as diversas texturas do chão da cidade: a diferença entre uma calçada e o asfalto, entre o úmido e o seco, o piso frio do inverno e escaldante sob o sol de verão. A água que se pisa contida na poça ou corrente na sarjeta a carregar sacos de lixo que antes se encontravam acumulados numa esquina. 
Caminhar pelo centro da cidade não carrega necessariamente o estigma da pobreza, ele vem com as marcas distintivas do craqueiro. Na "caminhada", a cidade torna-se destino. Uma visão tátil e nômade do mundo possibilitada pelos pés descalços que pagam o preço com as feridas abertas pelo desgaste. Quando não estão descalços, costumam estar, no máximo, separados do chão do asfalto e da calçada pela sola de um chinelo. Sujeitos, portanto, ao frio, a água e ao sol. O mundo das relações com os outros se encontra bem ancorado ao chão. Espalhar-se ou sentar-se na calçada é uma técnica corporal e manifestação de desdém pela opinião dos passantes sobre o que deva ser retidão moral. Quando se levanta, caminha com andar trôpego e os punhos fechados a esconder as pedras de crack que, desta forma, podem ser mais facilmente descartadas em caso de abordagem policial. Sob efeito do crack, o que pode significar estar mais sob efeito da privação do sono, da fome, do Corote, se anda pelas calçadas e praças sem tanta preocupação em desviar-se dos demais transeuntes, os obrigando a se precaverem de modo inusitado contra o esbarrão na figura humana que se aproxima em sentido contrário, com seu cobertor. O usuário de crack que não dorme há muitos dias comporta-se na calçada de modo semelhante ao carro na pista, sem grande capacidade de desviar-se, como pode fazer um pedestre. Pouco atento aos demais pedestres, o usuário cansado na "caminhada" também pouco desvia das pequenas obstruções que surjam rentes ao chão; se machuca. A percepção na "caminhada" é função do movimento com os pés, muitas vezes desnudos, sobre o chão. Percebe-se caminhando, um "conhecimento ambulatório" (INGOLD, 2015 [2011], p.88).

O hotel abre possibilidades distintas do cotidiano vivido sob os imperativos da droga. Um cotidiano marcado pelo perambular e pelo corpo fatigado, sedento e faminto corresponde uma mente propícia a sonhar acordada e despertar, para depois sonhar outras vezes até finalmente desligar na calçada. Portanto, o estado comparável ao zumbi, termo pejorativo utilizado pela mídia (FARINA ZANOTTO; ASSIS, 2017, p. 777) para se referir aos frequentadores da Cracolândia, ou seja, aquele no qual se sonha acordado. Não diz respeito à totalidade do que chamamos, em outra oportunidade (ALVES, 2017), de Ciclo alerta/sono do usuário de crack, mas apenas a uma parte. Mais especificamente àquela correspondente ao estado de movimento do corpo durante o sonho provocado por dias e dias de uso em estado alerta. Atribuir ao usuário de crack a alcunha de zumbi é tomar um estado particular de sua existência cotidiana e tê-lo por 
totalidade. Este estado é sucedido pelo sono propriamente dito, com o corpo em estado de repouso para em seguida poder despertar com a "mente limpa", ou seja, pronta para um "trago" mais prazeroso. ${ }^{5}$ Neste sentido, corpos e mentes sãovistos como um só. À mente alerta, corresponde um corpo em movimento, ao corpo fatigado, corresponde uma mente que sonha acordada. Esta, por vezes, pode estar mais desperta ou mais absorta em um sonho. A percepção embaralhada tem na realidade, o sonho e, no sonho, a realidade. Ele pode despertar e voltar a sonhar por inúmeras vezes e o corpo permanecerá em movimento, a acompanhar o usuário de crack em sua "caminhada". Ao cair definitivamente em um sono profundo, deitado em uma calçada ou mal acomodado em seu barraco, o usuário estará em condições de descansar um pouco mais profundamente, porém, para isso, pagou o preço de ir desfalecendo gradualmente em um longo processo de luta por permanecer um pouco mais semiacordado à custa do consumo de pedras de crack. Assim sendo, o que comumente se chama de binge, o uso de drogas até o completo esgotamento, pode ser mais bem-conceituado ao se levar em conta o usuário, seu corpo/mente em um ambiente a proporcionar pedras de crack. Pedras estas obtidas a partir do movimento em busca de fundos do "corre" e necessárias para manter um corpo/mente alerta até o embaralhamento de sonho com realidade. Se o uso de drogas em geral nos permite ter uma nova percepção da realidade, o uso do crack permite mesclá-la com nossos sonhos em um ambiente onde tudo parece conspirar para dificultar o descanso.

\footnotetext{
${ }^{5}$ Conforme nos declarou o ex-usuário Antônio, o trago ao despertar, ou seja, aquele dado "com a mente limpa" é mais prazeroso quando comparado àqueles dados apenas para manter-se acordado.
} 


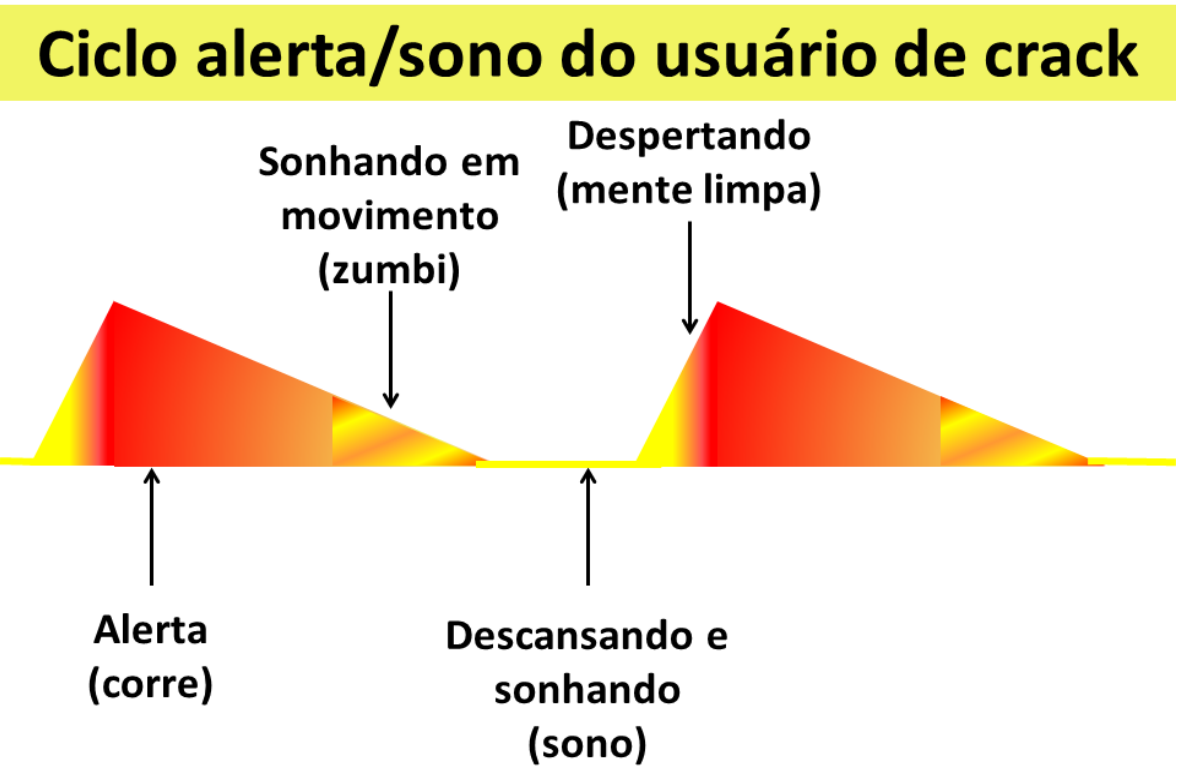

Figura 1 - Ciclo alerta/sono do usuário de crack.

Ter um local para dormir é fundamental para se romper com o ciclo alerta/sono do usuário de crack. Os dias passaram a ter uma cadência regida pelas três refeições diárias, pelo horário de trabalho de zeladoria pela manhã e pelo sono noturno proporcionado pela acomodação dos beneficiários como hóspedes em hotéis da região. Para alguns, esta carga diária de atividades foi ampliada pela participação em cursos de formação profissional, como os de jardinagem, além dos de informática, cabelereiro, entre outros. Isto tudo corresponde a uma gama de obrigações e responsabilidades a estruturar, no sentido de ordenamento do cotidiano, a vida dos usuários de crack. Criam-se responsabilidades quanto a horário, aparência, vestimenta, higiene, manutenção e manuseio de material didático e de trabalho. À mudança nas atividades que estruturam o dia a dia e no ambiente em que se vive corresponde uma alteração na relação da pessoa com a droga.

\section{Conclusão}

Considerando não haver ainda bibliografia disponível sobre esta inédita experiência que foram os hotéis do DBA, nos lançamos no desafio de os descrever e buscar as razões de sua resiliência. Este artigo procurou suprir esta lacuna através da análise de relatos etnográficos e entrevistas com profissionais de saúde, assistência 
dentro dos hotéis. O tipo e profundidade das informações que daí surgiram dependeram, grandemente, da qualidade das relações estabelecidas com nossos interlocutores. Em um movimento que foi das relações com eles para o saber sobre as relações entre eles.

O DBA foi um programa do município de São Paulo destinado ao atendimento das demandas levantadas entre as pessoas que residiam na rua e consumiam crack na região paulistana conhecida como Cracolândia, localizada no bairro da Luz, centro da cidade. Com caráter intersecretarial envolveu, primordialmente, as áreas municipais da Saúde, Assistência, Trabalho, Direitos Humanos e Segurança Urbana. Foi concebido para ofertar abrigamento, tratamento de saúde, alimentação, atividade ocupacional, capacitação profissional e auxílio financeiro aos beneficiários incluídos na execução de serviços de zeladoria.

Nos hotéis, inicialmente próximos ao "fluxo", com o tempo passam a ser de melhor qualidade e um pouco mais afastados. As equipes técnicas, contratadas no último ano do DBA, puderam aqui ser caracterizadas pela sua busca constante de maior confiança, empatia e vínculo com os beneficiários. Numa aproximação em que a vida parece ser contada em sussurros ao pé do ouvido, murmurada, assoprada por lábios que respondem e procuram o vínculo. Termo onipresente no discurso dos técnicos e agentes que trabalham na Cracolândia, vínculo, parece ser fruto da força de uma troca estabelecida através da escuta de qualidade, interessada e competente. Um encolher da distância como método gnosiológico, em que o morador do hotel pode ser transmutado em "caso", a ser objeto de trabalho de equipe, de diálogo, de debate, de busca por alternativas de solução das mais diversas demandas.

Vimos também como um local para dormir pode ter grande impacto sobre estrutura de vida da pessoa, composta por um importante conjunto de variáveis que se referem a padrões regulares de atividades laborais, recreativas e domésticas que moldam e constrangem o dia a dia de usuários de drogas.

A hospedagem em um hotel do DBA traz uma conquista política e contratual a partir da realização de assembleias genuinamente deliberativas. No entanto, a equipe técnica não abre mão de sua parcela de responsabilidade, não sobrecarregando os beneficiários com obrigações burocráticas em nome da democracia, com responsabilidades e decisões capazes de indispor uns com os outros. Portanto, existem 
assuntos que a equipe técnica não pode abrir mão de decidir sem correr o risco de prejudicar ou colocar um morador em perigo.

Por último, o estado semelhante ao zumbi, atribuído injustamente ao usuário de crack, pode ser superado ao se criar um ambiente com responsabilidades quanto a horário, aparência, vestimenta, higiene, manutenção e manuseio de material didático e de trabalho. Onde se possa dormir ao invés de ser obrigado a permanecer na rua. Ao se transformar o ambiente e o cotidiano, se muda a relação com a droga que pode ser mais favorável.

\section{Bibliografia}

ADERALDO, G.; FAZZIONI, N. Choro e samba na Luz: etnografia de práticas de lazer e trabalho na R. Gal. Osório, Ponto Urbe [Online], 11 | 2012, posto online no dia 01 Dezembro 2012, consultado o 06 Dezembro 2017. URL: http://pontourbe.revues.org/1159; DOI : 10.4000/pontourbe.1159

ADORNO, R. et al. Etnografia da cracolândia: notas sobre uma pesquisa em território urbano. Saúde \& Transformação Social/Health \& Social Change, v. 4, n. 2, 2013.

ADORNO, R. et al. Amarga delicia: Experiências de consumo de crack na região central de São Paulo (BR). Revista Inter-Legere, n. 15, p. 87-109, 2014.

ALVES, Y. D. D. Jamais fomos zumbis: contexto social e craqueiros na cidade de São Paulo. Salvador: Ed. UFBA, 2017.

ANTROPOLOGIA DAS DROGAS. Entrevista com Lumena Almeida Castro Furtado sobre o De Braços Abertos. Antropologia das drogas, São Paulo, 1 ago. 2017. Disponível em: https://www.youtube.com/watch?v=Z6mksk-nQ0o\&feature=share. Acesso em: 26 102017.

BECKER, Howard S. Outsiders: estudos de sociologia do desvio. Zahar, 2009.

BIDOU-ZACHARIASEN, C. "Introduction". In: BIDOU-ZACHARIASEN, C. (org.)., Retours en Ville. Paris: Descartes \& Cie. 2003. p. 9-43.

BIONDI, Karina. Proibido roubar na quebrada: território, hierarquia e lei no PCC. São Paulo: Editora Terceiro Nome, 2018. 
BOURGOIS, P. In search of respect: selling crack in El Barrio. Nova lorque: Cambridge University Press, 2006.

BOURGOIS, P.; SCHONBERG, J. Righteous dopefiends. Los Angeles: University of California Press, 2009.

CALIL, T. C. Relatos e imagens da cracolândia: modos de vida e resistência na rua, Cadernos de Arte e Antropologia, Vol. 5, № 2 | -1, 91-102. 2016.

COSTA, G.; LIMA, H. A loucura atrás das grades: recorte histórico da segregação dos indesejáveis. Revista Transgressões, v. 1, n. 1, p. 64-88, 2015.

DA SILVA, S.; ADORNO, R. A etnografia e o trânsito das vulnerabilidades em territórios de resistências, registros, narrativas e reflexões a partir da Cracolândia. Saúde \& Transformação Social/Health \& Social Change, v. 4, n. 2, 2013.

DEJOURS, Christophe. A loucura do trabalho: estudo de psicopatologia do trabalho. São Paulo, Cortez, 1988.

FARINA ZANOTTO, Daniele; BÜCHELE ASSIS, Fátima. Perfil dos usuários de crack na mídia brasileira: análise de um jornal e duas revistas de edição nacional. PhysisRevista de Saúde Coletiva, v. 27, n. 3, 2017.

FERNANDEZ, O. Coca light?: usos do corpo, rituais de consumo e carreiras de "cheiradores" de cocaína em São Paulo. 2007.327f.Tese (Doutorado) - Universidade Fedreal da Bahia, Faculdade de Filosofia e Ciência Humanas, Salvador, 2007.

FRÚGOLI JR., H.; CAVALCANTI, M. Territorialidades da (s) cracolândia (s) em São Paulo e no Rio de Janeiro. Anuário Antropológico, n. II, p. 73-97, 2013.

FRÚGOLIJR., H.; CHIZZOLINI, B. B. Moradias e práticas espaciais na região da Luz, Ponto Urbe [Online], 11 | 2012, posto online no dia 01 Dezembro 2012, consultado o 07 Dezembro 2017. URL: http://journals.openedition.org/pontourbe/1135

FRÚGOLI JR, H.; SKLAIR, J. El barrio de la Luz en São Paulo: cuestiones antropológicas sobre el fenómeno de la gentrification. Cuadernos de antropología social, n. 30, p. 119-136, 2009.

GARCIA, L.; TYKANORI, R; MAXIMIANO, V. Uma perspectiva social para o problema do crack no Brasil: implicações para as políticas públicas. In: BASTOS, F., \& BERTONI, N. Pesquisa nacional sobre o uso do crack: quem são os usuários de crack e/ou similares do Brasil? quantos são nas capitais brasileiras? Rio de Janeiro: ICICT/FIOCRUZ, 2014.

GOFFMAN, E. Manicômios, prisões e conventos. São Paulo: Perspectiva, 1987. 
GRUND, J. P. Drug use as a social Ritual: Functionality, symbolism and determinants of self-regulation. Rotterdam: Institute Voor Verslavingsondersoek, Erasmus Universiteit, 1993.

HERZFELD, M. Cultural Intimacy: social poetics in the Nation-State. New York: Routledge, 1997.

INGOLD, T. Estar vivo: ensaios sobre movimento, conhecimento e descrição. Petrópolis, Editora Vozes, 2015 [2011].

MAGALHÃES, T.Campos de disputa e gestão do espaço urbano: o caso da 'cracolândia' paulistana. 2015. Tese de Doutorado. Universidade de São Paulo.

MALHEIROS, L. S.Tornando-se um usuário de crack. In: NERY FILHO, A. et al. As drogas na contemporaneidade: perspectivas clínicas e culturais. Salvador: EDUFBA, 2012.p. 79-100.

."Entre sacizeiro, usuário e patrão": Um estudo etnográfico sobre consumidores de crack no Centro Histórico de Salvador. In: MACRAE, E. TAVARES, L. R.; NUÑES, M. E. Crack: contextos, padrões e propósitos de uso. Salvador: EDUFBA. 2013. p. 154-227.(Drogas: clinica e cultura).

MENEZES, L. F. Entre a saúde e a repressão - políticas públicas na região da 'Cracolândia' SP. 2016. Dissertação (Mestrado em Saúde, Ciclos de Vida e Sociedade) Faculdade de Saúde Pública, Universidade de São Paulo, São Paulo, 2016. doi:10.11606/D.6.2016.tde-18042016-142114. Acesso em: 2017-11-17.

MOTTA, A. População em situação de rua: contextualização e caracterização. Textos \& Contextos (Porto Alegre). 4 (1): 1-15, 2005. https://www.redalyc.org/articulo.oa?id=321527157003

NASSER, M. No labirinto: formas de gestão do espaço e das populações na Cracolândia. 2016. Dissertação(Mestrado em Sociologia) - Faculdade de Filosofia, Letras e Ciências Humanas, Universidade de São Paulo, São Paulo, 2016. Disponível em: <http://www.teses.usp.br/teses/disponiveis/8/8132/tde-10032017-142143/>. Acesso em: 2017-11-17.

PICHON-RIVIÈRE, Enrique. Teoria do Vínculo. 5.ed. São Paulo (SP): Martins Fontes, 1995.

PREFEITURA DE SÃO PAULO. Secretaria Municipal de Assistência e Desenvolvimento Social. Plano de assistência social do município de São Paulo. São 
Paulo, 2009.

https://www.prefeitura.sp.gov.br/cidade/secretarias/upload/assistencia_social/comas /arquivos/plas/plas 2009-2012.pdf

RAUPP, L. M.; ADORNO, R. Uso de crack na cidade de São Paulo/Brasil. Toxicodependências, v. 16, n. 2, p. 29-37, 2010.

ROMANINI, M.; ROSO, A. O Crack na Mídia Escrita: epidêmico, avassalado e diabólico. In: Anais da $3^{\circ}$ Jornada Interdisciplinar em Saúde. Santa Maria, 2010.

RUI, T. C. Corpos Abjetos: etnografia em cenários de uso e comércio de crack.2012. 335f. Tese (Doutorado em Antropologia Social) - Programa de Pós-Graduação em Antropologia Social, Universidade Estadual de Campinas, Campinas, SP, 2012.

RUI, T. et. al. Amarga delícia: experiências de consumo de crack na região central de São Paulo. Revista Inter-Legere, (15), 2014. 87-109.

RUI, T.; FIORE, M.; TÓFOLI, L.F. Pesquisa preliminar de avaliação do Programa 'De Braços Abertos'. Plataforma Brasileira de Política de Drogas (PBPD)/ Instituto Brasileiro de Ciências Criminais (IBCCRIM). São Paulo, 2016.

MACRAE, E.; SIMÕES, J. A. Rodas de fumo: o uso da maconha entre camadas médias urbanas. Salvador: EDUFBA, 2000.(Drogas: clinica e cultura).

SOUZA, L. C. Entre usuários e traficantes: Múltiplos discursos "sobre" e "da" atuação dos agentes de segurança na região da "cracolândia". 2015. Disserta ção de mestrado. Centro de Educação em Ciências Humanas, Universidade Federal de São Carlos, São Carlos, 2015

STRATHERN, M. Property Substance and Effect: Anthropological essays on persons and things. London: New Brunswick, NJ: Athlone Press, 1999.

TURNER, V. O processo ritual: estrutura e antiestrutura. Petrópolis, RJ: Vozes, 1974.

VELHO, Gilberto Cardoso Alves. Nobres \& anjos: um estudo de tóxicos e hierarquia. Editora FGV, 2008.

WISNIK, G.; CORULLON, M. Geometria da intervenção. Folha de São Paulo, São Paulo, 16 abr. 2006.2 Disponível em: http://www1.folha.uol.com.br/fsp/mais/fs1604200606.htm. Acesso em: 18102006. 
Dossiê | Os hotéis do Programa de Braços Abertos (ALVES, Ygor Diego Delgado; PEREIRA, Pedro Paulo Gomes)

YUNES, M. A. M. et al. Família vivida e pensada na percepção de crianças em situação de rua. Paideia, v. 11, n. 20, p. 47-56, 2001. http://www.scielo.br/pdf/paideia/v11n21/06.pdf 